\section{Journal of Architectural Research and Development}

Research in Contex

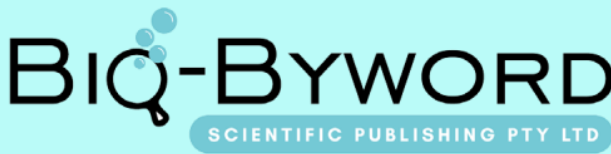

By Liu Chengxi, Liu Gongqing

\title{
Analysis of Architectural Planning and Environmental Protection
}

\author{
Qingdao Beiyang Architectural Design Co., Ltd. Qingdao, Shandong, 26600
}

\section{Impact of architectural} planning on the environment

1.1 In the architectural planning process, different levels of damage will be inevitably caused to the environment. The self-restoration ability of the natural ecosystem is limited, and if humans lose control in the reshaping process of nature to such an extent that the bearing capacity of the environment, we will be more likely to face a wide range of serious consequences such as resource depletion, environmental pollution and unsustainability. If we want to mitigate the damage of urban construction on the environment, we should have a very objective and accurate understanding of the development of local cities in the early stage of architectural planning, use scientific methods to calculate and analyze a series of restriction elements like the population bearing capacity, bearing capacity of water environment, bearing capacity of air environment, traffic bearing capacity of the region, cope with them by adopting reasonable planning techniques, thus minimize the damage of urban construction on the environment. "Green City" is a good planning concept for dealing with environmental issues in the process of urbanization and accepted by more and more city administrators. It fuses urban development elements such as environmental protection, economic development, science and technology, green ecology, together, to jointly build a sustainable development scientific planning system for sustainable development.
1.2 Low-carbon buildings are the key to build a green city. Therefore, we should minimize use of energy in the process of building material and equipment manufacture, during construction and within the full life cycle of buildings, which cover contents in aspects like land acquisition, planning, design, construction, and energysaving in building operation phase.

This kind of environment form of building environment is gradually development on the basis of people's increasing demand for the living environment and on the premise of social development. Taking building environment as an important part of urban environment has far-reaching significance in improving the residential environment and quality of life among urban residents. Buildings are naturally integrated into natural environment and safe, comfortable and convenient living, working, leisure and recreational environments are offered to people living in cities, contributable to enhancing people's sense of belonging to their cities ${ }^{1}$.

2. Relationship between architectural planning and environmental protection

2.1 Architectural planning work should be carried out within the bearing capacity of environment

Natural environment is the home we, the human beings depend on to survive and an extremely complicated system. It not only provides space and resources and contains wastes.

\begin{abstract}
With the rapid development of construction industry in recent years, urban construction has made substantial achievements, and the resulting construction pollution also become an important factor that affects the environment. As a forest of high-rise buildings have been erected in cities, a series of increasingly severe issues, such as noise pollution, air pollution, light pollution, are caused accordingly, which have considerable adverse influence on sustainable social development. To reduce the damage of urban construction on the environment, and create a harmonious relationship between humans and nature, we try to explore and integrate more scientific methods, advanced technologies and improved systems into architectural planning and build our beautiful home together.
\end{abstract}

Key words: architecture; environmental protection; relationship

Published online: 30th Sept, 2017

However, natural resources and containment of wastes are mostly limited, with constant population growth, resources per capita become scarcer, and human survival will face huge changes if the ecological balance is destroyed due to 
environmental pollution. Therefore, in the stage of architectural planning, we are required to carry out compre-hensive and elaborate research on various bearing capacities of cities, including the bearing capacity of land resources, the bearing capacity of water resources, the bearing capacity of air resources, under the guidance of the principle of sustainable development in the composite system of "society-economyecological environ-ment", so that the development of our cities goes safely and stably within the range of environmental bearing capacity.

2.2 Architectural planning should be unified with natural environment harmoniously

New homes are all ugly and ole homes are too shabby. Except for the landscape, artificialities are not worth seeing. The philosophy of creation and architecture of China's tradi-tional cities is particular about the union of heaven and humans between and pursues the formation of harmonious relationship between humans and nature, architecture and nature and the appearance of a sense of interdependence in architecture and natural environment. However, at present with the rapid develop-ment of social economy, fast-food architectural styles emerge in an endless stream. Each building hope to be able to be innovative and each building goes against natural environ-ment. Architecture is the art of solidification, and once built, it will have an impact on the city constantly in a period of dozens of years. If we wish to change the negative influence of the diffusion of this fast food culture, our designers should improve their self-accomplishment and professional skills and our management authorities should form effective controls and restriction in aspects like institutional construction and legislative supervision as well.

2.3 Attach importance to the guiding role of planning
The trend of urban develop-ment change rapidly, the age of fighting over policies and land is gone, if cities want to develop stably and healthily, planning guiding should be elevated to a very important position and adhered to throughout.

\section{Mutual balance and constraints of architectural planning and environmental protection}

Planning should be made before construction. Scientific planning is a basis for better develop-ment of cities and the most favorable measure for environ-mental protection. It contri-butes to reducing funds and waste of resources. The priority of planning focuses on taking environmental protection seriously. Architectural planning should follow the requirement of "Government organization, expert leading, department coordination and scientific decision" and reach the deve-lopment goal of "allow cities to be integrated into nature, residents look over the mountain, see the water, and remember the nostalgia" by means of scientific planning.

\section{Common measures for environmental protection in architectural planning}

To integrate the concept of environmental protection into architectural planning, practitioners need to learn and improve their own professional skills and increase professio-nalism. Here are common measures for environmental protection in the process of current architectural planning:

4.1 Prioritize the development of public transport

To mitigate the environmental pollution problems caused by people's dependence on motor vehicles, we advocate adoption of some new measures during the process of planning and design to ensure the priority of urban public transport, and encourage cities to vigorously develop and improve public transport system to reduce the utilization rate of private cars.

4.2 Smart retrenchment strategies for urban development

Most cities' urban development mode of extensive growth and borderless expansion for the past several decades brought many hard-to-solve disadvan-tages to the social economy and natural environment. New planning concepts encourage the planting of new industries and functions in the existing land, allow stock assets to produce great efficiency gains, carry out the refined transformation of urban built-up areas, and realized comprehensive Renaissance from the restoration of physical space restoration to the bridging of social differentiation ${ }^{2}$.

\subsection{Make full use of big data}

With the development of internet informatization, various big data are gradually applied in urban planning practice together with traditional data. The establishment of digital planning technological system cored on geographic information system, remote sensing, three-dimensional simulation and database offers new analysis tools and data support and surely will become a new trend for future planning development.

\section{4 Efficiently utilize new energy}

To cope with gradual depletion of traditional energy and environmental pollution pro-blems caused by it, we advocate that the application of new energy should be proactively guided in planning, renewable energy like solar energy, geothermal energy, wind energy, natural light and water energy, should be effectively and reasonably utilized and gradually take the place of traditional energy to reach energy saving and environ-mental protection goals.

\section{Conclusion}

In a work, if we want to realize coordinated development of both architectural planning and environmental protection, we 
need to make great efforts together, master and use new planning concepts and rely on the development of science and technology, the maturity of emerging technologies and improved systems to jointly build our beautiful home.

\section{References}

[1] Qi Haijun, Chen Bowu. Analysis on the Relationship Between Building Planning and Environmental Protection [J]. Green Environment Protection Building Materials, 2017,04: 48.
[2] Meng Xiaoqing. The Correlation Analysis Between Building Planning and Environmental Protection [J]. Low Carbon World, 2017,15: 134-135. 